Journal of Animal and Veterinary Advances 9 (16): 2109-2112, 2010

ISSN: $1680-5593$

(C) Medwell Journals, 2010

\title{
Involvement of the Central Monoaminergic System in Insulin-Induced Anorexia in Chicks
}

\author{
Jun-Ichi Shiraishi, Kouchi Yanagita, Hiromi Terao, Maki Matsuura and Takashi Bungo \\ Laboratory of Animal Behavior and Physiology, Graduate School of Biosphere Science, \\ Hiroshima University, Higashi-Hiroshima, 1-4-4 Kagamiyama, 739-8528, Japan
}

\begin{abstract}
Recent research has revealed the anorexigenic effects of insulin in the central nervous system associated with changes in the expression of hypothalamic neuropeptides such as neuropeptide $\mathrm{Y}$ or $\alpha$-melanocyte stimulating hormone. However, it is possible that monoaminergic system also participates in insulin-induced anorexia in chicks as suggested in early studies which show that changes in monoamine content play important roles in anorexia in mammals. To clarify the role of monoaminergic systems in the anorexic effect of central insulin in neonatal chicks, the levels of brain monoamines after intracerebroventricular injection of insulin were investigated. Although, there were no differences in the levels of adrenalin, 4-hydroxy3-methoxyphenylacetic acid, serotonin and 5-dihydroxyindole-3-acetic acid at each time point ( $p>0.1)$ and the level of noradorenaline in chicks treated with insulin were significantly lower than that with saline at $30 \mathrm{~min}$ post-injection $(\mathrm{p}<0.05)$. Conversely, dopamine and its metabolite, DOPAC were significantly increased in chicks treated with insulin when compared with the saline control $(\mathrm{p}<0.01)$. However, co-injection of dopamine receptor antagonist prolonged insulin-induced anorexia at 60 and $120 \mathrm{~min}$ post injection $(\mathrm{p}<0.05)$. These results indicate that the central noradrenalinergic but not dopaminergic and serotonergic systems may partly be involved in insulin-induced anorexia in neonatal chicks.
\end{abstract}

Key words: Central nervous system, insulin, monoamines, chicks, feed intake, anorexia

\section{INTRODUCTION}

Identifying peripheral signals that form in the Central Nervous System (CNS) is just one of several important steps in understanding how energy balance is regulated in most vertebrates (Schwartz et al., 2000). It is also critical to understand the neural circuitry upon which these peripheral signals act. It has been made more complicated by the large number of neurotransmitters that link to the control of feed intake and energy expenditure. These functional circuits focus upon the systems that receive the most direct input from peripheral satiety signals. Pancreatic insulin, in addition to its role as peripheral anabolic regulator also acts to control feeding behavior and energy homeostasis in mammalian CNS (Schwartz et al., 2000; Obici et al., 2002). Shiraishi et al. $(2008 \mathrm{a}, \mathrm{b})$ reported that insulin functioned as an appetite-suppressive peptide in the CNS of chicks and that the $\alpha$-melanocyte stimulating hormone ( $\alpha$-MSH) and the post-translational processing of Pro-Opiomelanocortin (POMC) mediates this role of central insulin (Shiraishi et al., 2008a, b). In mammals, the hypothalamic dopaminergic, serotoninergic and noradrenergic neurotransmitters research in conjunction with different appetites such as Neuropeptide Y (NPY) and $\alpha$-MSH to regulate feed intake (Orosco et al., 2000; Barber et al., 2003). There is however, no information on whether the monoaminergic system participates in insulin-induced anorexia in neonatal chicks. Thus, the levels of brain monoamines after intracerebroventricular injection of insulin and the effects of monoamine agent against insulin-induced anorexia were investigated.

\section{MATERIALS AND METHODS}

Day old male layer-type chicks (Single Comb White Leghorn) were obtained from a local hatchery (Akita Co. Ltd, Hiroshima, Japan) were maintained in a room with $24 \mathrm{~h}$ lighting and at a temperature of $30^{\circ} \mathrm{C}$. They were given free access to a commercial starter diet (Nichiwa Sangyo Co. Ltd., Kobe, Japan) and water during the pre-experimental period. They were distributed into experimental groups based on their body weight so that the average body weight $(52.8 \pm 0.4 \mathrm{~g})$ was as uniform as possible for each treatment. The birds were reared individually in experimental cages and had fed ad libitum

Corresponding Author: Takashi Bungo, Laboratory of Animal Behavior and Physiology, Graduate School of Biosphere Science, Hiroshima University, Higashi-Hiroshima, 1-4-4 Kagamiyama, 739-8528, Japan 
access to feed up to the time of experiments. All experimental protocols were approved by the Animal Experiment Committee of Hiroshima University. Porcine insulin was purchased from MP Biomedicals, Inc. (Aurora, $\mathrm{OH}, \mathrm{USA}$ ) and Haloperidol (HAL), dopamine D2, D3 and D4 receptor antagonist was obtained Sigma (St. Louis, $\mathrm{MO}$, USA). The drugs were dissolved in $0.85 \%$ saline containing $0.75 \%$ acetic acid. The birds ( 4 days old) received an Intracerebroventricular (ICV) injection of drug(s) or vehicle solutions $(10 \mu \mathrm{L})$ using a microsyringe according to the methods used by Davis et al. (1979). Each chick was injected once only with a dose of either drug or vehicle. Feed intake was determined by measuring the reduction in feed consumption from a pre-weighed feeder. The weight of feeders was measured using an electric digital balance of precision $\pm 1 \mathrm{mg}$. At the end of the experiments, birds were sacrificed by decapitation followed by brain sectioning to identify the location of the drug injection. Data were deleted from individuals in which the presence of Evans Blue dye in the lateral ventricle was not verified. In trial 1 , chicks were divided into three groups: 15,30 and $60 \mathrm{~min}$ after vehicle or insulin (100 ng) treatment. After measuring feed intake at the end of each treatment period, the chicks were sacrificed and the diencephalon collected for analysis of brain monoamine contents. The levels of brain Noradrenaline (NA), Adrenaline (A), Di-hydroxyphenylacetic Acid (DOPAC), 5-Dihydroxyindolacetic Acid (5-HПAA), Dopamine (DA), 4-hydroxy-3-methoxyphenylacetic acid (HVA) and serotonin (5-HT) were determined by HighPerformance Liquid Chromatography (HPLC) with an Electrochemical Detector (ECD) based on the earlier report (Bungo et al., 2008). In trial 2, birds were given free access to feed for $2 \mathrm{~h}$ immediately after each treatment. Chicks were injected with either vehicle, insulin ( $20 \mathrm{ng}$ ) or insulin co-injected with HAL ( 25 or $50 \mu \mathrm{g}$ ). The doses of antagonist applied here were based on preliminary trials at the levels that did not affect feeding behavior in ad libitum chicks. Feed intake was measured at 30,60 and $120 \mathrm{~min}$ post-injection. The data were analyzed using the commercially available package, StatVeiw (version 5, SAS Institute, Cary, USA, 1998). For comparisons between means of feeding and monoamines data in trial 1 , a Student t-test was done at each time point. For analysis of feeding data in trial 2, comparisons between means were made using the Tukey-Kramer test. Differences were considered to be significant when $\mathrm{p}<0.05$. Results are presented as mean \pm SEM.

\section{RESULTS AND DISCUSSION}

The effect of ICV injection of insulin on feed intake and concentrations of monoamines and their metabolites in brain tissue at 30 and $60 \mathrm{~min}$ post-injection are shown

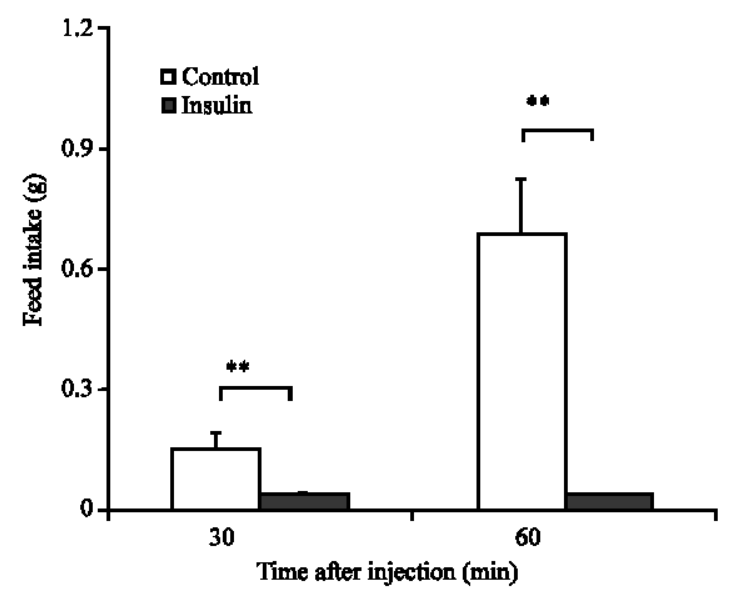

Fig. 1: Feed intake of chicks injected ICV with vehicle or insulin (100 ng) at 30 and $60 \mathrm{~min}$ after treatment. Data are presented as means \pm SEM of 3-4 chicks per groups. ${ }^{* *} \mathrm{p}<0.01$ compared with control group

Table 1: Effect of intracerebroventricular injection of insulin on brain monoamines and their metabolite concentrations at 30 and $60 \mathrm{~min}$ postinjection in ad libitum chicks

\begin{tabular}{lrlrr}
\hline Injection & \multicolumn{1}{c}{$30 \mathrm{~min}$} & & $60 \mathrm{~min}$ & \\
$\left(\mathrm{pg} \mathrm{\textrm {mg } ^ { - 1 } )}\right)$ & \multicolumn{1}{c}{ Control } & Insulin & Control & Insulin \\
\hline $\mathrm{NA}$ & $916 \pm 24$ & $820 \pm 15^{*}$ & $924 \pm 53$ & $844 \pm 53$ \\
$\mathrm{~A}$ & $69 \pm 4$ & $65 \pm 14$ & $62 \pm 6$ & $58 \pm 6$ \\
DA & $283 \pm 5$ & $351 \pm 17^{*}$ & $320 \pm 13$ & $340 \pm 25$ \\
DOPAC & $38 \pm 2$ & $52 \pm 2^{*}$ & $40 \pm 4$ & $48 \pm 4$ \\
HVA & $44 \pm 4$ & $53 \pm 2$ & $54 \pm 4$ & $58 \pm 3$ \\
5-HT & $1510 \pm 145$ & $1671 \pm 57$ & $1635 \pm 70$ & $1615 \pm 67$ \\
5-HIAA & $169 \pm 15$ & $187 \pm 11$ & $171 \pm 14$ & $166 \pm 16$ \\
\hline
\end{tabular}

NA, Noradrenalin; A, Adrenalin; DA, Dopamine; DOPAC, 3, 4dihydroxyphenylacetic acid; HVA, 4-Hydroxy-3-methoxyphenylacetic acid; 5-HT, serotonin; 5-HIAA, 5-dihydroxyindole-3-acetic acid. Data were presented as means \pm SEM. of 3-4 chicks per groups. $* p<0.05$ compared with control group

in Fig. 1 and Table 1. Central insulin injection resulted in reduced feed consumption compared with the control during $60 \mathrm{~min}$ experimental period $(\mathrm{p}<0.01)$. This is in good agreement with the earlier reports (Shiraishi et al., $2008 \mathrm{a}, \mathrm{b}$ ). The concentration of NA in ad libitum chicks treated with insulin was significantly lower than that of the control at $30 \mathrm{~min}$ postinjection $(\mathrm{p}<0.05)$. NA administration directly into the CNS increased feeding in chickens and chicks (Denbow and Sheppard, 1993; Bungo et al., 2010). It seems that central insulin suppresses NA release and is partly involved in the insulin-induced anorexigenic effect.

Conversely, DA and its metabolite, DOPAC were significantly increased in chicks treated with insulin when compared with saline control $(\mathrm{p}<0.05)$. However, there were no differences in the levels of A, HVA, 5-HT and 5-HIAA at each time point $(\mathrm{p}>0.1)$. Tong and Pelletier (1992) indicated that POMC-producing neurons are positively regulated by a central action of $\mathrm{DA}$ via $\mathrm{D}_{2}$ 


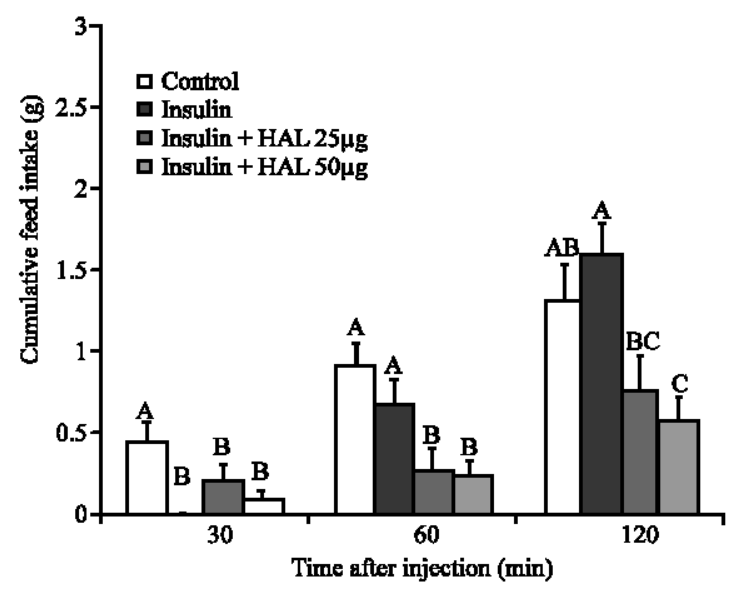

Fig. 2: Cumulative feed intake of ad libitum chicks injected ICV with vehicle, insulin (20 ng) or insulin co-injected with two doses of HAL ( 25 or $50 \mu \mathrm{g}$ ). The values were means \pm SEM of 7-8 chicks. Means with different letters at each time are significantly different at $\mathrm{p}<0.05$

receptors in the arcuate nucleus of rats. Recently, it found that the anorexic effect of insulin was due to $\alpha-\mathrm{MSH}$, a post-translational processing of POMC in neonatal chicks (Shiraishi et al., 2008a). Hence, there was a possibility that the anorexigenic effects of central insulin might be due to the activation of DAergic system as well as the central melanocortin system. We demonstrated the antagonistic effect of DAergic system on insulin-induced anorexia in the next part of this study.

The effect of co-injection of HAL, DA receptors antagonist (for D2, D3 and D4) on feed intake is shown in Fig. 2. Central administration of insulin and co-injection of two doses of HAL significantly decreased feed intake of ad libitum chicks when compared with the control at 30 min post-injection $(\mathrm{p}<0.05)$. Central insulin-induced anorexia disappeared at 60 and $120 \mathrm{~min}$ post-injection while co-injections of HAL caused lasting depression of feeding in chicks $(\mathrm{p}<0.05)$. Although, central DA had no effect on feeding behavior in chickens and chicks (Denbow et al., 1983; Bungo et al., 2001), the present results implied that DAergic systems positively regulated feeding behavior in insulin treatment chicks. Additionally, it seemed that the accelerated activation of DAergic system by central insulin was not involved in the anorexic effect of insulin. Further research on the interaction of central insulin and DAergic system on feed regulation is necessary in neonatal chicks. It was reported that central administration of $5-\mathrm{HT}$ induces anorexia in chicks (Sashihara et al., 2002). However, there were no differences in the level of 5-HT and 5-HIAA seen in the present study (Table 1). With regard to the central effect of insulin on 5-HT in rats, several views have been proposed: administration of 5-HT releasing drugs promoted the activation of central insulin nervous system (Orosco et al., 2000) while central injection of insulin showed delayed-action towards causing increased level of hypothalamic 5-HT. Hence, it is likely that insulin may indirectly affect the brain 5-HT and may also sustain other physiological regulations.

\section{CONCLUSION}

The present results indicate that central insulin affects the activities of the NAergic and DAergic system but not the serotonergic system in the brain of chicks. However, the NAergic but not DAergic, system may partly be involved in insulin-induced anorexia.

\section{ACKNOWLEDGEMENT}

This research was supported by a Grant-in-Aid for Scientific Research from the Japan Society for the Promotion of Science.

\section{REFERENCES}

Barber, M., B.S. Kasturi, M.E. Austin, K.P. Patel, S.M. MohanKumar and P.S. MohanKumar, 2003. Diabetes-induced neuroendocrine changes in rats: role of brain monoamines, insulin and leptin. Brain Res., 964: 128-135.

Bungo, T., K. Yahata, T. Izumi, K.I., Dodo and K. Yanagita et al., 2008. Centrally administered tryptophan suppresses food intake in free fed chicks through the serotonergic system. J. Poult. Sci., 45: 215-219.

Bungo, T., K. Yanagita and J.I. Shiraishi, 2010. Feed intake after infusion of noradrenaline, dopamine or its precursor into the lateral ventricles in neonatal chicks. J. Anim. Vet. Adv., 9: 760-763.

Bungo, T., S.I. Kawakami, A. Ohgushi, K. Sashihara and N. Saito et al., 2001. Intracerebroventricular injection of fusaric acid attenuates the anorexia by glucagonslike peptide-1 in the neonatal chick. Pharmacol. Biochem. Behav., 70: 251-255.

Davis, J.L., D.T. Masuoka, L.K. Gerbrandt and A. Cherkin, 1979. Autoradiographic distribution of L-proline in chicks after intracerebral injection. Physiol. Behav., 22: 693-695.

Denbow, D.M. and B.J. Sheppard, 1993. Food and water intake responses of the domestic fowl to norepinephrine infusion at circumscribed neural sites. Brain Res. Bull., 31: 121-128. 
Denbow, D.M., H.P. van Krey, M.P. Lacy and T.J. Dietrick, 1983. Feeding, drinking and body temperature of leghorn chicks: Effects of ICV injections of biogenic amines. Physiol. Behav., 31: 85-90.

Obici, S., Z. Feng, G. Karkanias, D.G. Baskin and L. Rossetti, 2002. Decreasing hypothalamic insulin receptors causes hyperphagia and insulin resistance in rats. Nat. Neurosci., 5: 566-572.

Orosco, M., C. Rouch and K. Gerozissis, 2000. Activation of hypothalamic insulin by serotonin is the primary event of the insulin-serotonin interaction involved in the control of feeding. Brain Res., 872: 64-70.

Sashihara, K., T. Bungo, R. Ando, A. Ohgushi, S.I. Kawakami, D.M. Denbow and M. Furuse, 2002. The role of central serotonergic systems on the regulation of feeding behavior of chicks in two different strains. J. Applied Anim. Res., 21: 17-23.
Schwartz, M.W., S.C. Woods, D. Jr. Porte, R.J. Steeley and D.G. Baskin, 2000. Central nervous system control of food intake. Nature, 404: 661-671.

Shiraishi, J.I., K. Yanagita, M. Fujita and T. Bungo, 2008a. Central insulin suppresses feeding behavior via melanocortins in chicks. Domest. Anim. Endocrinol., 34: 223-228.

Shiraishi, J.I., K. Yanagita, M. Fujita and T. Bungo, 2008b. $\mu$-opioid receptor agonist diminishes POMC gene expression and anorexia by central insulin in neonatal chicks. Neurosci. Lett., 439: 227-229.

Tong, Y. and G. Pelletier, 1992. Role of dopamine in the regulation of proopiomelanocortin (POMC) mRNA levels in the arcuate nucleus and pituitary gland of the female rat as studied by in situ hybridization. Brain Res. Mol. Brain Res., 15: 27-32. 